\title{
Challenges and Opportunities for Circular Economy Promotion in the Building Sector
}

\author{
Rafaela Tirado ${ }^{1,2, *(\mathbb{D})}$, Adélaïde Aublet ${ }^{1}$, Sylvain Laurenceau ${ }^{1}$ and Guillaume Habert ${ }^{2}$ (I) \\ 1 Scientific and Technical Centre for Buildings (CSTB), University Paris-Est, 24 Rue Joseph Fourier, \\ 38400 Saint-Martin-d'Hères, France; adelaide.aublet@cstb.fr (A.A.); sylvain.laurenceau@cstb.fr (S.L.) \\ 2 Sustainable Construction Department, IBI, ETH Zurich, Stefano-Franscini-Platz 5, 8093 Zürich, Switzerland; \\ habert@ibi.baug.ethz.ch \\ * Correspondence: tdeanira@student.ethz.ch
}

check for updates

Citation: Tirado, R.; Aublet, A.; Laurenceau, S.; Habert, G. Challenges and Opportunities for Circular Economy Promotion in the Building Sector. Sustainability 2022, 14, 1569. https://doi.org/10.3390/su14031569

Academic Editors: Anibal C. Maury-Ramirez and Jaime A Mesa

Received: 16 December 2021

Accepted: 21 January 2022

Published: 28 January 2022

Publisher's Note: MDPI stays neutral with regard to jurisdictional claims in published maps and institutional affiliations.

Copyright: (C) 2022 by the authors. Licensee MDPI, Basel, Switzerland. This article is an open access article distributed under the terms and conditions of the Creative Commons Attribution (CC BY) license (https:// creativecommons.org/licenses/by/ $4.0 /)$.

\begin{abstract}
The accelerated development of cities involves important inflows and outflows of resources The construction sector is one of the main consumers of raw materials and producers of waste. Due to its quantity and potential for recovery, waste from the construction sector constitutes significant deposits and requires major action by bringing together different stakeholders to achieve the objectives of a circular economy. Consequently, it is crucial to understand the current knowledge of urban metabolism, deposits, and recovery practices. This article aims to investigate the role of local authorities in the planning of strategies to facilitate a circular economy; in particular, this article aims to answer how local authorities facilitate circular economy initiatives in the building sector and what opportunities and obstacles they encounter in the process. The strategy used for the study was to conduct semistructured interviews with those responsible for circular economy projects within local authorities that were pioneering circular economy projects in metropolitan France. The results highlight the importance of community involvement in the implementation of circular economy principles in the building sector. Thus, it is essential to identify the different stakeholders and their respective challenges to build an operational framework.
\end{abstract}

Keywords: circular economy; local authorities; urban metabolism; interview; building

\section{Introduction}

The activities of the construction sector, which are still based on a linear economic model [1], are mainly responsible for Greenhouse Gas (GHG) emissions, the depletion of natural resources, and the production of a considerable quantity of waste [2-4]. The ecological context and recent health crisis have highlighted the imperative need for a more sustainable, circular, resilient, and inclusive economy. Circular Economy (CE) theory is based on the efficiency and optimization of the use of resources and the reduction of waste throughout the life cycle of goods and products while creating economic opportunities [5]. Because of its ecological and socioeconomic impact, the construction sector is considered a sector with a high potential to generate value and take advantage of practices at several scales.

Resource use efficiency has traditionally focused on production and consumption [6]; however, territories have the ability to manage and implement larger-scale CE strategies thanks to their roles in, for instance, urban planning and their relationship with economic players and their consequential understanding and mastery of urban metabolism. At the territorial level, the application of $\mathrm{CE}$ in the built environment requires collaborative, transdisciplinary work and multiscalar and prospective reflection to develop and apply strategies for better consumption, construction (production), and waste management. Consequently, local authorities can become the main catalysts for the development of economic dynamics, given their role within the territories. 
In this context, we interviewed various project managers involved in this transition toward a $\mathrm{CE}$, including local authorities that are pioneering the application and development of CE strategies in the construction sector because they recognize the challenges and opportunities of applying a CE due to the initiatives already undertaken in their jurisdictions. Our main goal was to understand their involvement in CE initiatives, strategies, and projects in their jurisdictions and to identify their main needs to encourage the application of CE in building sector projects. Identifying their current and future challenges and opportunities will allow others to be inspired and, above all, to proactively anticipate the challenges and opportunities offered by the transition to CE. This article focuses on the opportunities and challenges encountered by interviewed CE project managers in applying CE principles in the construction sector.

\subsection{Circular Metabolism}

Circular metabolism is the result of the fusion of CE and urban metabolism. The CE concept was first mentioned in the report "The potential for substituting manpower for energy" by the European Commission [7], which listed the reduction of energy consumption and job creation as objectives and concluded with a definition of the structure and nature of an "economy in loops". During the 2000s, in the context of the fight against climate change, the notion of CE took on much greater importance, based on the "cradle to cradle" theory ("from cradle to cradle") [8]. Then, the Ellen MacArthur Foundation, created in 2010, conceptualized the notion of CE that was later used in the 2013 reports of the European Commission [9]. In France, the concept of CE was widely disseminated during the Grenelle Environment Forum in 2007 [10]. Since then, the CE has been part of the public policies of state and local authorities as well as all of the city's stakeholders (LTEVEC law [11], EPCi law [12]). On February 10, 2020, the French Senate adopted Law No. 2020-105: the Antiwaste and the circular economy (AGEC) law [13]. The metaphor of urban metabolism has been widely used to describe territories as organisms that require resources to support their activities and generate waste during transformation processes. This interest in the study of urban metabolism has enabled the multiscale analysis of the flow and stock of resources and waste in a territory [14-22]. Circular metabolism, therefore, refers to the circulation of the flow of resources on a territorial scale so that the inputs of external resources are minimized to give rise to internal circular practices, in this way reducing environmental impacts and promoting sustainable and resilient territories.

\subsection{Circular Economy for the Construction Sector}

The building sector in France is responsible for a quarter of the national GHG emissions and consumes $43 \%$ of the total energy [23]. It also produces a large part of the construction waste, 40 million tons of waste per year on average [24]. This waste, which is mainly generated by demolition activities [25], partly feeds illegal dumps that are a real environmental and economic problem for communities [26].

Consequently, the AGEC law requires the construction sector to (1) promote the treatment of construction materials, equipment, and products during rehabilitation and demolition so that they do not become waste; (2) increase the use of reused materials in building construction or renovation projects; (3) plan and manage the deployment and networking of CE equipment (storage platforms, sorting centers, resource centers, and recycling facilities).

In summary, the implementation of the strategies of the AGEC law aims to reduce the flow of materials in the territories and the consequential consumption of resources and waste production through a value-retention process of resources (Figure 1). Estimation of resource requirements for built-up areas of the territory, identification of secondary resource deposits, quantification and identification of flows, as well as the development of valuation channels for secondary materials and land planning that will accommodate these resources, therefore, represent important issues for public authorities and communities to address in order to establish an efficient CE system. 


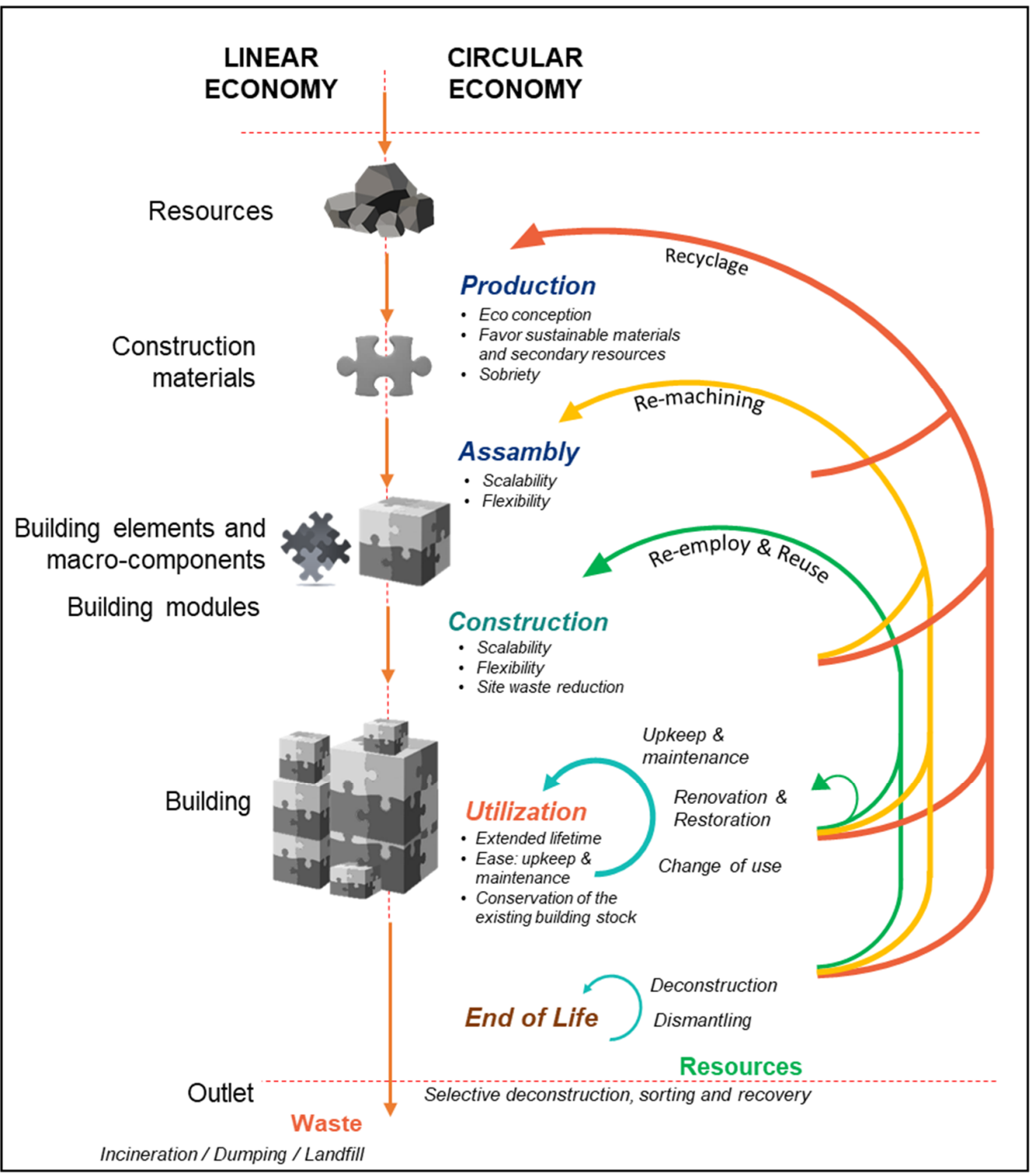

Figure 1. Levels of resource valuation for the construction sector. Inspired from the Ellen MacArthur Foundation, Circular economy diagram [27].

\subsection{Role of Territorial Authorities}

A local authority maintains various roles within its territory: (1) as the contracting authority, it manages the heritage of the territory; (2) it provides a financial boost in supporting economic activities, for instance, by linking community members and training activities; (3) as social housing financiers, the community finances the building or rehabilitation of social housing. In this context, the community has levers to mobilize landlords to incorporate CE practices; (4) as a planner, since the community manages land rights, it intervenes within the framework of local urban planning, for instance, in building construction or demolition permits. It can therefore facilitate, for instance, land for the establishment of secondary resource storage platforms; (5) as an administrator and pilot, the local authority signs contracts with planners to develop the territory. The town planning department manages these operations, and CE objectives can be included; (6) a local authority can deploy synergies between community members to codevelop strategies to apply a CE to the sector.

Faced with the challenges of transitioning to a $\mathrm{CE}$, communities can promote and apply the $3 \mathrm{R}$ (reduce, reuse, and recycle) concept to building materials during their own 
renovation or deconstruction work, that is, to act as an example. Another advantage is their leadership role, with which they can facilitate partnerships between different stakeholders in the development of their city and various other pioneering cities to promote a CE. They can also support technical developments by implementing tax breaks, for example, and promoting bottom-up initiatives (e.g., innovative ideas, exemplary projects).

\subsection{Territorial Diagnosis}

CE strategies at the territorial level revolve around several stages: a diagnosis of the territory, a roadmap, public initiation and support policies, and evaluation. To understand circularity, knowledge of a territory's flows is essential because the reuse and recycling channels require securing a supply of resources. A territorial diagnosis is applied to identify and quantify the material stocks and flows in a territory; this diagnosis will answer questions such as: What is the nature and quantity of material stocks and flows? What are the characteristics of waste flows, and how can they be reduced? Spatially and temporally, what are the characteristics and availabilities of resource deposits? What percentage of the flow is, for instance, revalued or recycled? What are the principal recycling and reuse channels in the territory? Which economic actors are involved?

Analysis of urban mines allows the identification of the materials present in the built stock in a territory and the deposits they form. A deposit comprises resources with similar characteristics sharing the same units of the constructive system, time, and space [28]. The material characterization of the stock and flows of buildings and deposits represents one of the main challenges for applying the CE. It represents the basis for the formulation of strategies for employment, opportunities, and the technical conditions for reintegrating resources into the economic loop by preventing them from becoming waste; because the better a material is known, the more efficient is its outlet.

\section{Materials and Methods}

Information was gathered by following a qualitative semistructured interview format $[29,30]$. This interview format allows the respondents' perceptions of complex issues such as the challenges and opportunities of the projects they participate in to be captured. The choice to follow a semistructured interview format was also made because it allows the respondents to express themselves freely and thus evoke subjects or problems that would not have been anticipated or identified in the formulation of our questions. Interviews were conducted by telephone or video conference. Representatives of three metropolitan areas or regions in France were interviewed, with 1 to 2 people interviewed at a time; details are given in Table 1. A total of 4 interviews were performed. The interviewees were experts and key people in circular economy projects, mainly managers of circular economy projects in territories that were pioneering CE strategies in their construction sector. Those interviewees were chosen because they presumably had a better viewpoint and understanding of the challenges and opportunities, thanks to the initiatives they had already carried out or that were in progress at the time of the interview. Interviews lasted approximately $45 \mathrm{~min}$ to 1.5 h. During the interviews, the interviewer took notes. In addition, most of the interviews were recorded if the interviewee agreed, and some interviews were transcribed if needed.

Table 1. Roles and locations of interviewees.

\begin{tabular}{ccc}
\hline Reference & Role & Location \\
\hline I-1 & CE and sustainable development project manager & Grenoble Metropolis \\
I-2 & CE and costs studies project manager & Paris City hall \\
I-3 & CE project manager & Lyon metropolis \\
I-4 & CE and energy transition project manager & Paris Region Institute \\
& Urban and territorial ecology researcher & \\
\hline
\end{tabular}


The interview guide (Appendix A) details the instructions for the interviewer as well as the semistructured questions related to (1) the interviewees' background in the subject of $\mathrm{CE}$; (2) the projects in which they have participated or are currently participating, project(s) in the city or region where CE strategies are applied, and more specifically, projects in the construction sector; (3) how the projects unfolded, the successes and obstacles encountered, how difficulties were approached, and their recommendations for facing these challenges. Finally, the interviewees were invited to mention their needs to improve the application of a CE in the construction sector at different territorial scales.

Principles of theoretical thematic analysis were used to analyze the information collected from the interviews [31]. The information was grouped into clusters under six key themes. Under these six themes, more specific subcategories were distinguished based on material obtained from the interviews. The analysis was collaboratively and iteratively performed by the coauthors to correctly interpret the information and reach a common understanding.

\section{Challenges and Opportunities}

3.1. Consideration of a Buildings' Life Cycle

3.1.1. Avoiding Deconstruction

A building is usually constructed for an intended lifespan of 50 years; however, its use will influence its longevity. The lifespan of a residential building is estimated to be between 70 and 100 years, while for a logistics or industrial building, it is only estimated to last 30 or 40 years [32]. Such a difference is not related to the structural resistance of the building but rather its profitability in terms of satisfying the needs of its investors; therefore, these buildings are often demolished or deconstructed before reaching their planned lifespan. As building construction is often inflexible and not adaptable to changes in future uses, buildings that are still in good condition undergo heavy renovations or are deconstructed for new construction. Interviewee I-3 mentioned: "the main issue is not waste, but how can we avoid deconstruction? Because today we sometimes deconstruct buildings when we do not need to". Therefore, today, deconstruction practices only strengthen the linear economy and increase environmental impacts. Consequently, deconstruction is still a sensitive issue because it is currently a common practice and can take yet some time to change if stakeholders are not aware of the subject and if they do not enact strategies to communicate and change this practice. In the context of circularity, buildings are intended to be preserved instead of deconstructed through regular maintenance, restoration, and renovation activities. Deconstructing a building should be the last resort if the building can offer adequate structural and sanitary conditions. Moreover, when this stage has arrived, it is necessary to institute a selective dismantling and deconstruction process because dismantling an element without damaging it allows it to be reinserted in the circular chain, allowing resources to be better separated and their reuse and recycling to be optimized.

\subsubsection{Selective Deconstruction}

Obtaining secondary materials at the end of a project and preventing them from becoming waste requires direct action at the source of the deconstruction sites by carrying out a selective deconstruction of building components. Selective deconstruction consists of a sequence of activities to help separate and sort building elements and materials [33]. Article 74 of the AGEC law [13] requires that "Any producer or holder of construction and demolition waste sets up sorting of waste at the source and when the waste is not treated on-site, a separate collection of wastes, especially for wood, mineral fractions, metal, glass, plastic, and plaster".

Successful selective deconstruction requires rigorous upstream preparation and the willingness and ability of stakeholders to adapt. In terms of deconstruction, environmental and economic viability must be assessed. According to the authors of [34], environmental sustainability will depend mainly on the characteristics of the building to be deconstructed as well as on local secondary resource markets. Resource diagnoses must also be carried 
out to dismantle and sort the elements as well as possible; for this, technical experts must be trained and sensibilized.

\subsection{Knowledge of Territorial Resources}

The application of a CE, given its interdisciplinarity and the large number of constituents it involves, can increase the number of complex practical questions.

At the end of life of a project (for instance, an urban project or a building project), it is essential to have an efficient waste management perspective, but for circularity, it is also essential to prevent outgoing resources from becoming waste. This requires knowledge of the resources (e.g., their nature, quantity, and state) to initiate and apply procedures to give the outgoing materials a second life.

Understanding the spatial and temporal composition and organization of stocks and flows is a major issue both for researchers [17-19,35] and communities: Interviewee I-3 highlights that "There is a whole issue around knowledge, knowledge sharing; therefore, both knowing the quality of the existing building, knowing the building stock material composition". To enhance the value of resources, it is necessary to have a detailed description of the resources and the deposits: I-2, speaking about the deposits, explained that "we would mainly need a characterization of the materials and the state of the materials ... It would be useful to have files on resource inventories, for example". That is, it is important to (1) identify the materials present in the urban mine and the potential receiving sites; (2) identify the economic actors and operators to reinsert the elements into the economic loop; (3) identify the sources offered by the possibility of developing reuse and recycling channels; (4) orchestrate the logistics of resource flows [28]. I-1 confirmed this need for information about deposits and building stock materials: "There is work to structure the visibility of resource diagnoses to know exactly where, when, and in what state they are available; from there, we can know if they can be used on our operations".

The interviewees shared their experience and their need to characterize the deposit and material flow in the building sector. I-1 explained that Paris has some initial elements of a territorial diagnosis that allow understanding of the waste flows of its building sector based on the studies of the Paris Urbanism Agency (APUR). This expert mentioned that: "To calculate the portion of inert, nonhazardous and hazardous waste in Paris, the APUR used a waste ratio production for building typologies and their historical knowledge of certain buildings. They currently have different needs to create reuse platforms according to the target material (for instance, concrete and gypsum). Consequently, we need a more detailed analysis [than inert, hazardous or nonhazardous waste] to identify companies that will agree to treat specific waste and reuse materials. Moreover, concerning the land areas and quantities of materials, we need to know what is relevant and what is anecdotal".

In turn, I-3 explained that for the metropolis of Lyon, "we have the first elements of diagnosis but they are not very precise ... We carried out an urban metabolism study with a technical office; the study was based on standard data and a table of inputs and outputs of economic flow (in euros) in the territory; then, material flows were estimated (in tons) ... The downside of this tool is that if we improve the reuse and recycling of materials, or the reduction of material consumption in the territory, it is unclear how the tool is converting the inputs and outputs in euros into material flows in tons; as long as we spend these euros, it appears that we are continuing to produce and consume ... Therefore, this tool provides an order of magnitude, but it does not reflect reality in the territory, in particular, related to our progress".

For the Grenoble metropolis, I-2 mentioned that "the metropolis has jurisdiction over household waste and wastes of a similar nature and composition (DMA) but not over professional waste ... Within the framework of the CODEC (Contract for Waste Objective Circular Economy), which has been signed, what is asked of us by ADEME is to model and quantify the flows: (1) The flows of DMAs ... For these flows, we have all the elements to be able to quantify them since we are the ones who collect them and we are the ones who process them; (2) they also asked us to quantify and model the flows of construction 
and public works in our territory and ... of what is called waste from economic activities (DAEE). On the other hand, both regarding the flow in the construction industry and in DAEE, we have no visibility".

\subsubsection{Spatial Scale}

An assessment scale is defined by geographical, economic, social, and administrative parameters. In a circular economy, the scale is instead defined according to the influences of an urban development project; that is, concerning the geographical perimeter, it is a question of acting rather locally, with an extended network of administrative and socioeconomic actors to promote partnership exchanges [28].

I-3 explained: "If we are working at the building scale, we need to know the quality of the materials and which sector they can go to; can they be reused or recycled, and so on... At the district scale, it is preferable to prepare for mass reuse and recycling. At the metropolis scale, a macro analysis is needed to structure the material sectors". I-2 specified: "We realize that we are all in our territories trying to create material reuse channels and each territory will perhaps have to specialize in one flow or in a main flow and secondary flow. However, there is no territory that will be able to handle all of the buildings' flows because there are too many of them. Today, we are still using newly emerging economic models. There are storage issues that are important; there are also transformational issues. Therefore, we thought that perhaps the best scale was the regional scale so that everyone could see how to process and target one or two flows to have at least a more significant number of flows processed. It appeared to be a relevant scale to us. Therefore, all deposits need to be identified, materials need to be reconditioned, and transformation needs to occur. In addition, after that, outlets need to be identified ... All of that is very difficult to set up in each territory. Suddenly, it occurred to us that maybe the reuse sector could be at a regional scale and the deposits could be at the metropolitan scale".

I-1 indicated: "I think that, in fact, you have different problems depending on your perspective, whether you are in a very dense urban, dense urban, rural or semirural area. The needs are not at all the same because, quite simply, the deposit is not the same, and the possibilities of creating platforms are not the same. Therefore, I think that when you are in a rural or semirural environment, you can plan more efficiently at the department or urban community level. You must have a large enough deposit volume to be able to create platforms and have a large enough territory. When you are in an urban or semiurban environment, it is even a little more problematic than in rural areas. Then, I think that there is one more elements to consider: the need for transit platforms. It is necessary to have an existing offer for these platforms. The supply must be substantial enough to justify these short-term and medium-term investments in terms of economic return. For this reason, it is difficult to say what the scale is because it depends on the territory in which we are located. Then, this answer will vary depending on, once again, whether you are located in a site that is urban, urban-dense, etc. In addition, you also need to find land, which is not easy in urban-dense areas ... Therefore, for me, it is difficult to think along lines of district collectives, intermunicipalities, departments, and regional scales".

\subsubsection{Temporal Scale}

I-2 mentioned: "Indeed, the modeling of the built stock of territory allows us to know its urban mine, but it does not give the full picture (dynamic) of this urban mine; it can perhaps be built there and never become waste. Therefore, we instead need to set up treatment channels or reuse channels for the quantity of waste in a territory at a given time. Because the problem, particularly in the reuse sector, is that if we do not have these elements, it is difficult for this sector to emerge ... What interests me much more today is to have information on work sites that are being planned ... or are in progress, which effectively gives information on the potential deposits, because in areas where we do not have any deposits, we simply have a snapshot in time of the urban mine". 
I-1 explained: "In my opinion, we need foresight. In addition, we know that today, buildings represent an important source and that this is where the significant issue lies in terms of reuse and recycling ... Everything that is not made of earth, concrete or stone has to be built. Thus, if everything is to be built, the first step is always to know and take stock of both what we have and, at the same time, the prospects to evaluate the issues, and from there, to be able to determine actions".

In Section 3.2, Preliminary results from BTP-Flux project [22] were shown to the interviewees to better frame the study and meet the needs of the CE. BTP-Flux considered various needs that were expressed by the interviewees regarding several points: (1) it allows a detailed description, including the nature and quantity, of the materials present in the building stock and the demolition waste flow (a more refined resolution than inert, hazardous, and nonhazardous waste); (2) the results can be obtained at different territorial scales in France (for instance, departmental, regional, and national-territorial divisions); depending on the availability of data, the study could be applied to finer territorial scales such as neighborhoods or districts; (3) the model also aims to assess the robustness of the results to be able to communicate reliable results to possible users (for instance, local authorities and building stock managers). The interviewees' feedback on the model results was positive and affirmed that it addresses the primary issue: knowledge of the material building stock and waste flow. It will allow them to diagnose their territory and then formulate optimal CE strategies in the construction sector.

In conclusion, the application of the circular economy must consider a multiscalar approach. For example, for the sustainable and circular management of a certain category of waste, the articulation of the different scales for the characterization of deposits, creation of transit platforms, and possible outlets is essential to identify the actors but also to ensure solidarity between territories and avoid pressure between them. Construction or urban development projects are quite long; therefore, the integration of circular economy strategies must consider the evolution of projects at different time scales. For instance, the construction materials present in built stock can be mobilized in the medium term during the maintenance or renovation of projects or, in the long term, at the end of a project. Therefore, it is necessary to have dynamic images of the deposits to plan the development of progressive strategies. This generates a need for data on the material stock composition and deposits and the information should include uncertainties about these availabilities.

\subsection{Census and Synergy of Actors-Organizational Brakes}

The interdisciplinary and dynamic nature of the circular economy involves a diversity of construction actors with various missions and skills. The CE needs the involvement of all the constituents in a city's development to be effective, including those who already work together and those who are not used to working together. That is, they need to think about, articulate, and agree on common environmental, technical, and economic objectives from the design stage, through production, until the end of the building's lifespan, and reinsert secondary materials in the economic chain. Each of these constituents plays a role that will contribute to the success of the transition.

The role of communities is to develop synergies between actors, that is, to manage governance. Governance is characterized by the development of the capacity for promotion and collaboration between actors. The project's governance is based on the sharing and complementarity of the stakeholders' skills in various areas of the city's development (housing, mobility, environment, town planning, etc.). The main goal of this governance is to converge the strategic (coherent and effective policies) and operational (application of the $\mathrm{CE}$ in projects) parts of the application of the seven pillars of the circular economy in a sector, taking into account the temporal and spatial scales influencing its projects.

Strengthening the link between all the players is therefore essential to move toward an iterative approach to harmonize working methods and modes of operation. To achieve this, the construction sector players must have a clear vision of the issues; in this sense, public figures can put in place strategies to raise awareness and train their constituents on 
integrating CE issues into their territory, foster the capacity to work collaboratively, and benefit from the collective intelligence.

Referring to a circular economy experience in their territory, I-1 mentioned: "It showed that to be able to do it, we needed to inventory the structures that were made using ecodesign and development, structures that transformed, ensured, restored, and were verified in their adaptability, and were compliant with technical performance in relation to use, etc. Therefore, we needed this collaboration of construction sector players. I think that this needs to be known and that all the actors are kept informed".

\subsubsection{Training and Awareness}

The training and awareness of stakeholders throughout the life cycle of a project is essential to encourage them to consider the challenges and levers raised by the $\mathrm{CE}$ and thus evolve current linear practices. It is about changing mentalities and practices both in the short term and in the long term; for example, on how to design a project, carry out diagnosis, or articulate the networks and sectors, as well as on enhancing and integrating reuse in construction projects. Today, few professions are entirely dedicated to the circular economy; currently, it is more a question of adapting the skills of professionals in other professions.

To act at a building or regional scale, we must train the technicians performing the diagnoses so that they can correctly diagnose the materials and identify those that can be reused, re-employed, or recycled and how it will be done. The feedback from local authorities was clear. I-1 explained: "In deconstruction, several issues need to be resolved. The first is the qualification and training of the actors, particularly the diagnosticians, so that they integrate the notion of reuse and have knowledge of the materials ... For me, one of the challenges is in this qualification and training, because to diagnose, one must reconcile both the knowledge of materials in the building sector and the knowledge of waste and potential sectors for reuse and recycling. Moreover, there is no interaction today between these two components, and the objective is that these diagnosticians will speak to each other; or better yet, that the same person can carry out both functions of this diagnosis". Therefore, training and requalification of professionals will allow them to adapt to this evolution in the sector and respond to new demands. "The second issue is, of course, whether there will be training and qualification work for architects, project managers and companies on this new [reuse] technique, including inspection offices, so that authorities know exactly how to deal with unusual techniques related to reused materials".

\subsubsection{Control and Monitoring of Demolition Crews}

I-1 quoted: "The other issue is the control and monitoring of demolition crews. Today, they know how to deconstruct ... it is not a question of knowledge, but there are two issues: for them, deconstructing can generate a hardship for their staff and a loss of productivity. Therefore, for these two reasons, and given their economic model, deconstruction requests are complicated. In addition, in any case, if we ask them to do something, whatever it is, there is work to be done in order to be able to monitor and control what they actually do because even if we apply regulations, enforcing them can be difficult. In fact, what would be interesting is if we did not assume a policing role, but instead, the process would come naturally for these crews... that they would not only be sensitized to the issues, but that they suddenly find technical and economic means to deconstruct in a more natural way, with cost sharing between the client and the demolition company. Therefore, there is something to be done ... I do not think we have a choice but to go through control and monitoring at the beginning, but it is exhausting and it is not satisfying to play this role of police officer; and I think that there is an issue, in any case, with that approach. I think that if several clients demand it, it will be done, but in any case, it will be done with reluctance. Thus, I think the best approach would be for the trade chambers to take interest in this subject and understand that it is also in their interest to find the levers for a new technical and economic model". 


\subsection{Traceability and Profitability}

\subsubsection{Waste Traceability and Digitization}

Traceability is defined according to ISO 9000: 2015 as "the implementation or location of an object (3.6.1)", and it also states that "in the case of a product, it can be linked to the origin of materials and components, production history, distribution and location of the product after delivery". In summary, the main objectives in the building-waste sector are (1) to compile the information to follow the flows and share them with all the players involved. This information may relate, for instance, to the identification of waste streams and their collection, preparation, treatment, transport, and performance checks, and (2) to understand the technical performance issues of a resource to ensure its quality and be able to reinsert it more quickly into the economic loop, thereby increasing its value.

The development of traceability models is, therefore, a significant challenge. I- 1 explained that "if we truly want to recycle materials, there is a need to get more information from a company than what it receives from the manager of its processing company. Upstream of the deconstruction, we chose to examine traceability; in fact, we did not settle for the information we received from the massification platform; we asked where it was going beyond that ... We also asked for documents attesting that the companies' treatment facilities are ICPE (Installations classified environmental protection) certified, and that they had the proper authorizations or declarations for their activities. This control was extremely laborious and complicated to deliver, but it made it possible to ensure that we were working with a third party that respects the rules, which is not a given, even today. Downstream, we systematically asked for the company to follow up with a photo of their dumpster. From there, we asked if it could be posted online on a document management platform, and that was truly useful in allowing us actually to invoice what was removed and follow up. This is how we discovered, in particular, that inert waste ultimately did not go to recycling but to landfills. So that is fundamental for me. In addition, I think that on this point, there is upstream traceability work to be done so that it is not up to each client to re-ask every one of their service providers for authorizations as well as their secondary outlets".

The traceability of the waste will allow us to adequately follow up on the waste throughout its treatment and ensure the compliance of the sectors in terms of ICPE regulations, for example, as mentioned by $\mathrm{I}-1$. It is, therefore, necessary to have reliable tracking slips. In addition, article L541-2 of the Environmental Code mentions that "Any producer or holder of waste is responsible for the management of this waste until its elimination or final recovery, even when the waste is transferred for third party processing". Article 36 of the CCAG (General and technical administrative clauses of works) considers the producer as the owner and the holder as the contractor.

With respect to this point, article 106 of the AGEC law specifies that "the person in charge of the waste collection facility must deliver free of charge to the company having carried out the work a deposit slip specifying the origin, nature, and the quantity of waste collected". In addition, "the company that carried out the work mentioned must be able to prove the traceability of the waste from the sites for which it is responsible by keeping the slips issued by the waste collection facility. The company that has carried out the work sends the slips to the commissioner of the work or the competent authority mentioned in article L.541-3 at their request".

The development of waste treatment platforms is evident. It is clear today, after feedback, that there is a significant lack of traceability tools and that the sector must adopt new digital tools to promote traceability and therefore optimal flow management. I-1 mentioned, "today, it is a paper document which is distributed, passing from hand to hand between different actors ... Therefore, the issue is digitization, so that suddenly it is not a paper document, but slightly more computerized, with a tablet or other device, at the moment the work begins until it arrives at its final outlet. With digitization, it would be possible to link actors, create networks for accessing data and help decision-making. Having the information in real-time will also make it possible to observe any slippages and react 
quickly; for example, an operator who, despite alerts, sent the waste to an unauthorized service provider". Certain waste traceability tools, such as "Trackdéchets" [36], a digital version of the monitoring slip for hazardous waste, are being developed by the public authorities in France. This type of device could be extended to other types of waste and could give project owners better visibility of what happens to their waste once a platform takes it.

The traceability of site waste coupled with digital tools can meet several needs, including the quantification of flows and real-time monitoring of resources, the increase and control of their quality and possibly a reduction of the costs of waste treatment due to the better overview of their origin, and the ability to share information so that each stakeholder can be made aware of their responsibility throughout the treatment chain, from the site to the outlet; this would make the system more reliable and encourage stakeholders to improve their waste recovery.

\subsubsection{Performance of Secondary and Regulatory Brakes}

Speaking on secondary resources, I-1 explained: "we still have the whole problem of testing to verify the performance of these materials in the context of their use". Moreover, indeed, the use of secondary materials has slowed down because of (1) the properties and quality of the secondary resources recovered and (2) the regulations, standards, or insurance not yet being ready because there are still problems related to testing the performance of these materials for their intended use because they are not homogeneous. Therefore, the owners and insurers, who may not be confident about the technical and sanitary quality of the resources (for instance, stability, flexibility, resistance to deformation, strength), may hesitate to use them in their projects.

The main challenge is the coordination between all the stakeholders in the project. Contracting authorities can stipulate the use of reused materials in their contracts. Then, the intervention step will be for architects to identify in their first sketches the potential deposits or macroelements of the project that are likely to use reused elements by relying on specialized resellers. One of the sites that censuses these suppliers is Opalis [37]. Then, building element and material quality checks can be supported by experienced craftsmen, so that if the materials meet expectations (for instance, technical and sanitary expectations), they can be used, and insurers can include them. In addition, even if it can be challenging to know the performance of reused and recycled materials, if not impossible, the construction industry should make its best effort to maintain the materials' value as much as possible by addressing the $3 \mathrm{R}$ principle.

Another obstacle to using secondary resources is that the stakeholders do not yet have feedback on the cost-effectiveness of applying CE throughout the material's value chain. I-3 explained, "I think that feedback is still rare, but from what I understand, reuse or recycling requires more upstream engineering. However, afterwards, it saves costs downstream. Therefore, basically, you have to anticipate all the flows. Furthermore, I do not know that the additional engineering costs compensate for the avoided costs downstream; that is always the big question. In any case, there is a displacement of costs". At the territorial level, actions to massify waste flows are not yet common; nevertheless, they would be necessary to optimize profit from infrastructure investments required to manage secondary resources. At the material or product level, recycling costs remain mostly high compared to the prices of certain raw materials, so producers will favor virgin materials over recycled materials given their price. In addition, current product prices do not incorporate the price of their environmental impact, and the environmental quality of a product is not yet a major asset for its marketing.

\subsection{Massification and Storage Platforms and Land \\ 3.5.1. Platforms}

Resource collection and recovery companies are essential to better manage waste. In France, site waste can be transported to a network of community or professional waste 
collection centers. Companies specializing in waste management carry out waste collection at construction sites, incorporating several steps dedicated to different waste categories; then, all of the waste flow will converge on aggregation, sorting, or processing platforms or go directly to recovery or disposal outlets [38].

The regrouping, sorting, and pretreatment platforms are established with multiple objectives: (1) collect waste, (2) offer local solutions, (3) sort waste off-site when sorting on-site is not possible, and (4) optimize the costs of disposal (by negotiating with the disposal and final recovery channels). Currently, for the treatment of inert waste, there are specific platforms for this type of waste; however, most nonhazardous waste in the sector is managed by multiactivity platforms that can both receive industrial and/or household waste, which makes listing them more complex compared to platforms that are dedicated only to construction waste [38].

The sector needs to develop new recycling channels, in particular for the treatment of insulation and joinery. Some producers may decide to invest directly in the development of these sectors since the law makes it possible to reduce their environmental impacts when they participate directly in achieving the collection objectives in article 72 of the AGEC law. It is clear that the players wish to avoid being confronted with economic difficulties at all costs. By articulating public contracts, ecomodulations, and incorporated regulatory rates, extended producer responsibility (EPR) must "strengthen the links between demolishers, recyclers, producers of materials and construction companies, in order to find effective solutions together".

\subsubsection{Storage and Land}

The availability of land is also necessary to store the materials to stabilize deposits. One of the main advantages of communities is their administration of public land. Dedicated spaces or areas for the storage, sorting, and treatment of fixed and temporary materials should be zoned and included in town planning documents, or communities must provide land to store material according to the sites scheduled in the territory. I-1 explained, "the problem is also to find storage to be able to ensure the stability of, or guarantee, the deposit... Between the deposit and the transformation, there is a need for a space for storage ... At the same time, it is necessary to know whether, in the public domain, there is land that could be vacant temporarily or for longer term, on which we could set up massification facilities. This subject is complicated because those in charge of operations in town planning or elsewhere are subject to an eventual work plan that evolves with politics ... An inventory of the installations must then be performed. The objective in theory is to identify the residual capacities of the installations to know if they can accept this increase in work linked to urban changes ... The final consideration is to know if there is any potentially land in the public domain ... The challenge now is to find available land to continue to work on this issue and the need to communicate with and educate elected officials on these issues to try to study the prefeasibility of the platform on this land. Then, we will try to move forward gradually so that we can eventually land on reuse and recycling platforms".

\subsection{Toward a New Territorial Cohesion}

The transition to a circular economy in the construction sector will involve demonstrating opportunities to develop new economic perspectives so that the sector helps the territory become attractive. Attractiveness requires a revitalization of the territory by creating jobs and economic activities resulting from the initiatives taken by political and socioeconomic figures. These new economic activities can be the development of waste treatment and management, reuse, and recycling channels. The emergence of projects with a high locally added value will increase a territory's resilience because it will secure resources and optimize territorial ecosystems. Collective intelligence, territorial cooperation, innovation, and awareness-raising among stakeholders can become the new development engine. The local authorities' unique roles as facilitators, guides, and catalysts of new, 
practical circular initiatives can accelerate changes in current practices and the transition to new ones.

For the territories, more comprehensive questions arise, including the articulation of other regional plans such as the PCE (Climate Energy Plan), the biodiversity plan, urban travel plans, and the circular economy plan. In addition, the interaction of geographical and temporal scales of the circular economy, its multidisciplinary nature, and its governance requires the decompartmentalization of activities and establishment of hybrid thinking; that is, making mixed action systems worthwhile because today's silo-type organization is no longer tenable. Moreover, this transversality goes further, for instance, when sharing data, planning, and implementing actions and strategies. Currently, it is still difficult to access what is now considered confidential information to identify, for example, whether one project's waste can become another's resource; this requires transparency in details that are sometimes kept private; therefore, cooperation is required.

\section{Discussion}

The circular economy is presented today as a tool that can energize our territories by linking stakeholders in a process that incorporates solidarity, proximity, and applicability at all scales, and transverses all levels of the territorial structure. The implementation of the circular economy is essential to the development of a circular metabolism and is the key to helping cities reduce their ecological footprint and orient them toward resilience and sustainability. The main levers for the territories are their reductions of quantities of waste to be treated and imported raw materials, the relocation of their supply of materials by including secondary materials in the loop, and their creation of local jobs and development of a social, unified economy.

The building sector is one of the priority sectors for achieving the CE objectives and will involve many economic players in the production of buildings at several scales and beyond the buildings' life cycles. Deploying the circular economy at the stock level is essential because it will provide a better understanding of the flows of materials, energy, water, and goods. This makes it possible to target the priority sectors and resources where interventions will be necessary. In addition, it will allow identification of the players and the missing pieces needed to create valuation loops. Finally, innovative systems can be created by setting up scenarios and strategies to improve circularity and link specific complementary actors and organizations and diminishing traditional systems by creating hybrid development ecosystems.

To succeed in this transition, local authorities acting as facilitators, catalysts, and regulators can promote the development of $\mathrm{CE}$ by raising the identified challenges and taking advantage of the opportunities they offer.

One of the main opportunities is to prevent outgoing materials during building renovation or deconstruction, stopping them from becoming waste. Therefore, the main challenge is to increase the recovery rate; for this, it is necessary to know the nature, quantity, and temporal and spatial organization of the material flows and deposits. However, there are still a large number of technical challenges to address, mainly the integration of circularity clauses such as selective deconstruction and reuse in the contracts before deconstruction. Moreover, it is important to diagnose structures because there are specificities for new and existing buildings. Existing buildings are not easily removable, and in addition, the buildings may have undergone renovations or maintenance, and the materials may therefore be of different ages and conditions; in addition, they are not standard. Thus, the person doing the diagnostic evaluation must be made aware and trained to correctly identify all the materials and technical points and, with his/her diagnosis, to increase the degree of recovery of materials and products during deconstruction. At the territorial level, upward flow models can be potential tools in formulating CE strategies, particularly for establishing territorial logistics for managing secondary resource processing infrastructures and ensuring transparency on local channels. 
The building sector also has challenges related to the lack of communication between actors and a broad short- and long-term vision of the impacts of the sector's activities throughout and beyond the life cycle of its projects. In addition, given the relatively long lifespan of projects, the complexity of the fleet, and the number of stakeholders involved, it can be challenging to assign responsibilities to stakeholders at a specific stage of the entire life cycle of projects, buildings, and/or products. Nevertheless, the sharing of collaborative strategies and tools can offer a better overview of the built stock and deposits, tools such as shared databases, and common and appropriate methods to carry out deconstruction and manage secondary resources. To achieve this, stakeholders can communicate on certain cases and implement research and innovation within their structures to develop resources to facilitate CE deployment.

Technological factors can play an essential role in the lack of tools and digital logistics systems. The development of applications or platforms to stimulate this market will make it possible to promote materials better; in addition, digital tools and the sharing of information between stakeholders can help with the monitoring of resources from their diagnosis, highlighting their potential for development until they arrive at the appropriate outlets.

The sector must face resistance to change that is rooted in certain actors; awarenessraising and training of stakeholders is key not only for the deployment of actions but also for the generation of jobs, the creation of new professions, and the development of economic opportunities within the territories. From an organizational point of view, the main challenges and opportunities are to map the stakeholders and the territorial issues, then activate a territorial coordinator to facilitate the development of strategies and public policies to promote cooperation between stakeholders. Public authorities have the ability to find consensus for the application of the $\mathrm{CE}$ at different scales and levels, to provide normative and regulatory support for the management of resources, and to help stakeholders by reducing administrative procedures; they can also, for instance, give tax incentives to exemplary actors.

Social and cultural challenges are essentially linked to the lack of interest, knowledge, and/or commitment to applying CE strategies; in this context, communities have an opportunity to lead by example with their projects, by promoting collaboration between actors and by participating in the education, training, and qualification of the actors. Communities also have the opportunity to develop short- and long-term partnerships to promote the deployment of the CE. Social challenges also provide the opportunity to create social ties and consciousness to shape resilient, inclusive, circular, and sustainable territories.

\section{Conclusions}

The reduction of resource consumption, as well as the optimization of material use, prevention and improvement of waste management, and reduction in environmental impacts over the entire life cycle (and beyond) of building and building stock have become priority issues in the construction sector, which is faced with alarming signs of climate change and resource scarcities. These issues encompass actions relating to design, engineering, and management of materials, buildings, the building stock, and their cycles of use, maintenance, renewal, and deconstruction. All these actions mobilize many construction players who will contribute to their applicability, the consolidation or adaptation of existing sectors, and the development of new EC sectors in their territories while generating local jobs.

This article presents the results of semistructured interviews carried out with managers of CE projects in cities that are pioneering CE strategies in their construction sectors. The study highlights some of the main challenges and opportunities that interviewees raised within their territories, based on their experience. First, a life-cycle, multiscale, and multicriteria approach is required to meet the challenges of circularity in the construction sector. Then, the key to knowing the territory involves knowledge of its resources (for instance, materials, wastes, construction players, material sectors) to ensure the materials' circulation and traceability while relying on collaborative tools and technologies. All this 
will be possible only if there is increased awareness among stakeholders, allowing them to collaborate to pool resources and tools and develop synergies. Pioneer communities and actors are called upon to strengthen support and training to increase the skills of stakeholders and future professionals. The approaches also need to consider applicability to other subjects and sectors such as environmental, economic, sanitary, and social sectors. The results of this study can help construction stakeholders develop action plans in favor of a CE that can share visions, objectives, timeframes, and even common scopes that can take different forms, such as roadmaps and strategies.

Author Contributions: Conceptualization, methodology, formal analysis, investigation, resources, and data curation: R.T., S.L., A.A. and G.H.; writing-original draft preparation: R.T.; writingreviewing and editing: S.L., A.A. and G.H.; visualization: R.T.; supervision: S.L., A.A. and G.H. All authors have read and agreed to the published version of the manuscript.

Funding: The research presented in this article is part of the research work of the Ph.D. thesis of the first author planned from 2018-2022; this research is funded by the CSTB-funding number: 18.000835.01.01.

Institutional Review Board Statement: Not applicable.

Informed Consent Statement: Not applicable.

Data Availability Statement: Not applicable.

Acknowledgments: The authors would like to thank all the interviewees.

Conflicts of Interest: The authors declare no conflict of interest.

\section{Appendix A}

Interview guide

1. Instructions for the Interview

The research was done by interviewing the managers of circular economy projects in the municipalities of France. During the interviews, experiences, challenges, needs, and opportunities to promote the circular economy project in the building sector were discussed.

The participants were first approached by email, where they received a general overview of the interview subject and context. Interviews were conducted by telephone or video conference and recorded if the interviewees agreed. Notes were taken in every interview and were later used in the analysis and refined based on the recordings. Interview results were anonymous.

The main questions addressed concerned the application of circular economy strategies in the construction sector within their jurisdictional boundaries:

- What strategies are adopted in the territory in terms of CE in the construction sector?

- What is the scale of the projects' scope, and what is the projects' nature according to the action scale?

- In projects in which CE strategies have been implemented, what were and/or are still the main challenges and opportunities to CE strategy implementation?

- In a potential model of material flow assessment, what kind of information-qualitative or quantitative - will be needed to facilitate the implementation of CE strategies?

- $\quad$ Based on the interviewee's experiences, what scale would be relevant for the analyses of deposits?

- In your projects, what are the main data or information needs to facilitate or improve their CE strategy application? 


\section{References}

1. Anastasiades, K.; Blom, J.; Buyle, M.; Audenaert, A. Translating the circular economy to bridge construction: Lessons learnt from a critical literature review. Renew. Sustain. Energy Rev. 2020, 117, 109522. [CrossRef]

2. Krausmann, F.; Schandl, H.; Eisenmenger, N.; Giljum, S.; Jackson, T. Material Flow Accounting: Measuring Global Material Use for Sustainable Development. Annu. Rev. Environ. Resour. 2017, 42, 647-675. [CrossRef]

3. Ghisellini, P.; Ripa, M.; Ulgiati, S. Exploring environmental and economic costs and benefits of a circular economy approach to the construction and demolition sector. A literature review. J. Clean. Prod. 2018, 178, 618-643. [CrossRef]

4. Pomponi, F.; Moncaster, A. Circular economy for the built environment: A research framework. J. Clean. Prod. 2017, 143, 710-718. [CrossRef]

5. Witjes, S.; Lozano, R. Towards a more Circular Economy: Proposing a framework linking sustainable public procurement and sustainable business models. Resour. Conserv. Recycl. 2016, 112, 37-44. [CrossRef]

6. Weterings, R.; Bastein, T.; Tukker, A.; Rademaker, M.; de Ridder, M. Resources for Our Future: Key Issues and Best Practices in Ressource Efficiency; Amsterdam University Press: Amsterdam, The Netherland, 2013.

7. Stahel, W.; Reday-Mulvey, G. Jobs for Tomorrow: The Potential for Substituting Manpower for Energy. Available online: https: //www.researchgate.net/publication/40935606_Jobs_for_tomorrow_the_potential_for_substituting_manpower_for_energy (accessed on 28 April 2021).

8. McDonough, W.; Braungart, M. Cradle to Cradle-Remaking the Way We Make Things; North Point Press: New York, NY, USA, 2010.

9. Ellen MacArthur Foundation. Towards a Circular Economy: Business Rationale for an Accelerated Transition. Available online: https://www.ellenmacarthurfoundation.org/publications/towards-a-circular-economy-business-rationale-for-anaccelerated-transition (accessed on 28 April 2021).

10. Ministère de la Transition Ecologique. LOI n ${ }^{\circ}$ 2009-967 du 3 août 2009 de Programmation Relative à la Mise en CEuvre du Grenelle de L'environnement (1). Available online: https:/ / www.legifrance.gouv.fr/loda/id/JORFTEXT000020949548/ (accessed on 6 May 2021).

11. Ministère de la Transition Ecologique. LOI n ${ }^{\circ}$ 2015-992 du 17 Août 2015 Relative à la Transition Énergétique Pour la Croissance Verte. Available online: https:/ / www.legifrance.gouv.fr/dossierlegislatif/JORFDOLE000029310724/ (accessed on 6 May 2021).

12. Légifrance LOI n ${ }^{\circ}$ 2015-991 du 7 Août 2015 Portant Nouvelle Organisation Territoriale de la République (1). Available online: https:/ / www.legifrance.gouv.fr/loda/id/JORFTEXT000030985460/ (accessed on 6 May 2021).

13. Ministère de la Transition Ecologique. LOI n ${ }^{\circ}$ 2020-105 du 10 Février 2020 Relative à la Lutte Contre Le Gaspillage et à L'économie Circulaire (1)-Légifrance. Available online: https:/ / www.legifrance.gouv.fr/jorf/id/JORFTEXT000041553759/ (accessed on 6 April 2021).

14. Augiseau, V.; Barles, S. Studying construction materials flows and stock: A review. Resour. Conserv. Recycl. 2017, 123, 153-164. [CrossRef]

15. Augiseau, V.; Kim, E. Spatial characterization of construction material stocks: The case of the Paris region. Resour. Conserv. Recycl. 2021, 170, 105512. [CrossRef]

16. Lanau, M.; Liu, G.; Kral, U.; Wiedenhofer, D.; Keijzer, E.; Yu, C.; Ehlert, C. Taking Stock of Built Environment Stock Studies: Progress and Prospects. Environ. Sci. Technol. 2019, 53, 8499-8515. [CrossRef] [PubMed]

17. Kleemann, F.; Lederer, J.; Rechberger, H.; Fellner, J. GIS-based Analysis of Vienna's Material Stock in Buildings. J. Ind. Ecol. 2017, 21, 368-380. [CrossRef]

18. Stephan, A.; Athanassiadis, A. Towards a more circular construction sector: Estimating and spatialising current and future non-structural material replacement flows to maintain urban building stocks. Resour. Conserv. Recycl. 2018, 129, $248-262$. [CrossRef]

19. Heeren, N.; Hellweg, S. Tracking Construction Material over Space and Time: Prospective and Geo-referenced Modeling of Building Stocks and Construction Material Flows. J. Ind. Ecol. 2019, 23, 253-267. [CrossRef]

20. Schiller, G. Urban infrastructure: Challenges for resource efficiency in the building stock. Build. Res. Inf. 2007, 35, 399-411. [CrossRef]

21. Barles, S. Society, energy and materials: The contribution of urban metabolism studies to sustainable urban development issues. $J$ Environ. Plan. Manag. 2010, 53, 439-455. [CrossRef]

22. Tirado, R.; Aublet, A.; Laurenceau, S.; Thorel, M.; Louërat, M.; Habert, G. Component-Based Model for Building Material Stock and Waste-Flow Characterization: A Case in the Île-de-France Region. Sustainability 2021, 13, 13159. [CrossRef]

23. Ministère de la Transition Écologie et Solidaire Chiffres clés du Climat-France, Europe et Monde. Available online: https: / / www.statistiques.developpement-durable.gouv.fr/chiffres-cles-du-climat-france-europe-et-monde-edition-2019 (accessed on 28 April 2021).

24. European-Union Eurostat by Statistical Office of the European Union. Available online: https://ec.europa.eu/eurostat/data/ database (accessed on 28 February 2020).

25. Lützkendorf, T. Sustainability in Building Construction-A Multilevel Approach. In Proceedings of the IOP Conference Series: Earth and Environmental Science; Institute of Physics Publishing: Prague, Czech Republic, 2019; Volume 290. [CrossRef]

26. Adème; Ecogeos. Caractérisation de la Problématique des Déchets Sauvages; France; 2019. Available online: https://www.actuenvironnement.com/media/pdf/news-33455-etude.pdf (accessed on 12 September 2021). 
27. Ellen Macarthur Foundation Circular Economy Diagram. Available online: https://ellenmacarthurfoundation.org/circulareconomy-diagram (accessed on 14 February 2021).

28. Bellastock REPAR \#2; 2018. Available online: https: / www.bellastock.com/projets / repar-2/ (accessed on 24 April 2021).

29. Miles, J.; Gilbert, P. A Handbook of Research Methods for Clinical and Health Psychology; Oxford University Press on Demand: New York, NY, USA, 2005.

30. Gill, P.; Stewart, K.; Treasure, E.; Chadwick, B. Methods of data collection in qualitative research: Interviews and focus groups. Br. Dent. J. 2008, 204, 291-295. [CrossRef] [PubMed]

31. Braun, V.; Clarke, V. Using thematic analysis in psychology. Qual. Res. Psychol. 2006, 3, 77-101. [CrossRef]

32. Swiss Life Group What is the Lifespan of a House? Available online: https://www.swisslife.com/en/home/hub/what-is-thelifespan-of-a-house.html (accessed on 20 April 2021).

33. European Commission. EU Construction and Demolition Waste Protocol and Guidelines. Available online: https:/ / ec.europa.eu/ growth/content/eu-construction-and-demolition-waste-protocol-0_en (accessed on 12 May 2021).

34. Pantini, S.; Rigamonti, L. Is Selective Demolition Always a Sustainable Choice? Waste Manag. 2020, 103, 169-176. [CrossRef]

35. Augiseau, V. Using construction materials as secondary resources: Constraints and perspectives for territorial policies. Flux 2020, 116-117, 26-41. [CrossRef]

36. Ministère de la Transition Écologique et Solidaire Trackdéchets I La Traçabilité des Déchets en Toute Sécurité. Available online: https:/ / trackdechets.beta.gouv.fr/ (accessed on 5 May 2021).

37. FCRBE Opalis. Available online: https:/ / opalis.eu/fr (accessed on 5 May 2021).

38. FFB; Adème. Guide de Conception et de Fonctionnement des Intallations de Traitement des Déchets du BTP; Paris, France, 2014. Available online: https://www.seddre.fr/media/guide-de-conception-et-de-fonctionnement-des-installations-de-traitementdes-dechets-du-btp.pdf (accessed on 26 February 2020). 